\title{
Qualidade fisiológica de sementes de soja esverdeadas em diferentes tamanhos
}

\author{
Fábio Faustini Pardo ${ }^{1}$, Flávio Ferreira da Silva Binotti ${ }^{1}$, Eliana Duarte Cardoso $^{1}$, Edilson \\ Costa $^{1}$ \\ ${ }^{1}$ Universidade Estadual de Mato Grosso do Sul, Unidade Universitária de Cassilândia, Cassilândia, Mato Grosso do Sul, Brasil, \\ E-mail: flavio_agro@hotmail.com,binotti@uems.br, elianacardoso@uems.br, mestrine@uems.br
}

Recebido: 14/08/2015; Aceito: 15/09/2015

\section{RESUMO}

O tamanho da semente e o estágio de maturação podem influenciar a qualidade fisiológica das sementes. O objetivo foi avaliar a influência da semente esverdeada e tamanho das sementes na qualidade fisiológica de sementes de soja. O presente trabalho foi desenvolvido na Universidade Estadual do Mato Grosso do Sul na Unidade Universitária de Cassilândia, localizada no município de Cassilândia - MS. O delineamento experimental foi inteiramente casualizado em esquema fatorial 2x2, constituído por tamanhos (peneiras 5,75 $\mathrm{mm}$ e $6,5 \mathrm{~mm}$ ) e tipos de sementes (normais e esverdeadas), com cinco repetições cada. Realizaram-se avaliações de vigor e germinação. Sementes de soja esverdeadas apresentam menor potencial fisiológico e na mesma quanto menor o tamanho menor será a sua qualidade fisiológica.

Palavras-chave: Glycine max L., tamanho da semente, clorofila na semente, germinação, vigor.

\section{Physiological quality of green soybean seeds in different size}

\begin{abstract}
The seed size and maturation stage can influence physiological seed quality. The objective was to evaluate the influence of green seed and seed size on physiological quality of soybean seeds. This study was conducted at the Universidade Estadual do Mato Grosso, in the municipality of Cassilândia - MS. The experimental design was completely randomized in a $2 \times 2$ factorial design, consisting by size (sieves $5.75 \mathrm{~mm}$ and $6.5 \mathrm{~mm}$ ) and seed types (normal and greenish) with five replications each. Carried out assessments of vigor and germination. Greenish soybean seeds have lower physiological potential and in it the lower the lower size will be their physiological quality.
\end{abstract}

Keywords: Glycine $\max$ L., seed sizer, chlorophyll in the seed, germination, vigor. 


\section{Introdução}

A produção brasileira de soja, sobretudo no CentroOeste, região dos cerrados, tem sido afetada por um fenômeno também preocupante em outros países: a retenção de clorofila nas sementes. Os cotilédones apresentam vestígios do pigmento verde e a consequência verificada na produção de sementes é o decréscimo do vigor e da viabilidade. Sementes esverdeadas, tem propiciado prejuízos na emergência em campo, dificultando a formação de estandes recomendados para as diferentes cultivares, assim como muito descarte de lotes de sementes, no momento de semeadura devido à baixa qualidade fisiológica (ZORATO et al., 2007).

Plantas de soja, sujeitas aos estresses de origem bióticos (doenças de raiz, de colmo e de folhas; intenso ataque de insetos) ou abióticos (deficit hídrico decorrente de seca ou veranico durante as fases finais de enchimento de grãos e de maturação, principalmente se associado a elevadas temperaturas), que resultam em morte prematura ou maturação forçada, poderão produzir sementes e grãos esverdeados, o que resultará em acentuada redução das suas qualidades fisiológicas, além de severa redução da produtividade da lavoura (FRANÇA-NETO et al, 2012). O manejo inadequado de lavouras de soja também pode resultar na produção de semente esverdeada. A distribuição inadequada de calcário ou de fertilizantes pode ocasionar problemas de maturação desuniforme, o que, por sua vez, resultará na colheita de semente imatura e esverdeada, mesclada com semente amarela e madura (FRANÇA-NETO et al, 2005).

Para a maioria das cultivares de soja, a quantidade de clorofila diminui durante o processo de maturação, em função da atividade enzimática da clorofilase que degrada a clorofila resultando na expressão da coloração amarelada normal da semente. A ocorrência de períodos quentes e secos, durante os últimos estágios de maturação da semente, pode provocar a morte prematura da planta e, consequentemente, a maturação forçada da semente. Essas condições também podem cessar a atividade de enzimas (clorofilase) antes de toda clorofila ser degradada (RANGEL et al., 2011).

Rangel et al. (2011) verificaram que os acréscimos dos percentuais de sementes verdes provocam redução acentuada da germinação e do comprimento de raiz, porém, sem implicações nos teores e na acidez do óleo. Zorato et al. (2007) verificaram que as sementes esverdeadas de soja apresentaram menor germinação, viabilidade e vigor, maior desuniformidade de plântulas, taxa de deterioração e quantidade de lixiviados, menor comprimento de plântulas e massa de mil sementes e baixa capacidade de emergência em campo.

A qualidade fisiológica das sementes, representada pela viabilidade e vigor, pode influenciar diretamente muitos aspectos do desempenho, como, por exemplo, a taxa de emergência e a emergência total, sendo também o tamanho de semente outro componente da qualidade que vem sendo avaliado para muitas espécies (PÁDUA et al., 2010). Quanto maior o tamanho das sementes maior será a quantidade de fotoassimilados depositados (maior tecido de reserva disponível - maior massa), sendo a massa das sementes diretamente proporcional ao vigor das sementes. Sementes de maior tamanho poderão, em condições adversas, propiciarem uma emergência mais rápida e uniforme. Desta maneira, a classificação das sementes em peneiras propicia maior precisão na semeadura mecânica.

Os resultados em relação a influência do tamanho das sementes são controversos, sendo necessários novos estudos. Ávila et al. (2008) verificaram que quando se utilizam sementes provenientes de peneiras 5,5 e 7,0 $\mathrm{mm}$ a produtividade da soja não diferiu entre si, todavia Pádua et al. (2010) evidenciaram que sementes menores (peneira 4,0 $\mathrm{mm}$ ) proporcionam plantas com menor altura na colheita e produtividade em relação a peneira $6,0 \mathrm{~mm}$, e que sementes maiores apresentaram maior potencial fisiológico.

Neste trabalho objetivou-se avaliar a influência da semente esverdeada e tamanho das mesmas na qualidade fisiológica de sementes de soja.

\section{Material e Métodos}

O presente trabalho foi desenvolvido no Laboratório de Análises de Sementes da Universidade Estadual do Mato Grosso do Sul (UEMS) na Unidade Universitária de Cassilândia (UUC), localizada no município de Cassilândia - MS, nos meses de maio e junho de 2014.

O delineamento experimental foi inteiramente casualizado em esquema fatorial $2 \times 2$, constituído por tamanhos das sementes (peneira 5,75 $\mathrm{mm}$ e $6,5 \mathrm{~mm}$ ) e tipos de sementes (normais e esverdeadas), com cinco repetições cada.

Foram utilizados dois lotes de sementes de soja da variedade Anta 82, de tamanhos distintos em função dos tipos de peneiras utilizadas, peneira $5,75 \mathrm{~mm}$ e outra 6,5 $\mathrm{mm}$, com massa de mil sementes, em média de 130 gramas e 160 gramas respectivamente, produzidos na safra 2013/2014. Posteriormente, em cada peneira foram separadas em duas classes (tipos); sementes com coloração normal e sementes esverdeadas. As sementes foram submetidas as seguintes avaliações descritas a seguir:

Teste de germinação: Foi realizada com quatro subamostras de 50 sementes. As contagens foram realizadas aos 5 (Primeira contagem de germinação) e 8 dias (Germinação total) após a semeadura, de acordo com os critérios estabelecidos pelas Regras de Análise de Sementes (BRASIL, 2009). 
Índice de velocidade de germinação (IVG): Foi realizado em conjunto com o teste de germinação, onde o índice de velocidade para cada tratamento foi calculado segundo a fórmula proposta por Maguire (1962).

Teste de condutividade elétrica: Realizado por meio de quatro subamostras de 50 sementes, sendo mensurado de cada subamostra (repetições) a massa das sementes. A seguir as mesmas foram colocadas para embeber em um recipiente contendo $75 \mathrm{~mL}$ de água deionizada (3-5 $\mu \mathrm{S} \mathrm{cm} \mathrm{cm}^{-1}$ de condutividade), e então mantida em uma câmara (germinador) à temperatura de $25^{\circ} \mathrm{C}$ durante 24 horas. Após, o período de 24 horas foi realizado a leitura da condutividade elétrica na solução de embebição em condutivímetro. Os resultados foram

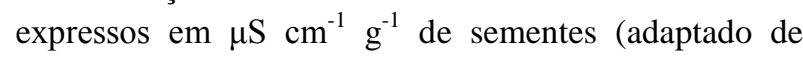
VIEIRA; KRZYZANOWSKI, 1999).

Teste de emergência: Foi conduzido em casa de vegetação utilizando quatro subamostras de 50 sementes por tratamento, com semeadura realizada à $1 \mathrm{~cm}$ de profundidade em bandejas tendo como substrato areia grossa. Considerou-se como plântulas emergidas com comprimento da parte aérea não inferior a $20 \mathrm{~mm}$ aos 8 dias após a semeadura. Os resultados foram expressos em porcentagem de plântulas emergidas.

Índice de velocidade de emergência (IVE): Foi conduzido em casa de vegetação juntamente com o teste de emergência de plântulas. As avaliações foram realizadas mediante a contagem diária do número de plântulas emergidas até 8 dias após a semeadura e o cálculo do índice de velocidade foi efetuado conforme formula de Maguire (1962).
Os dados foram avaliados por meio da análise de variância pelo teste $\mathrm{F}$ ao nível de $5 \%$ de probabilidade. Foi utilizado o programa SANEST, Sistema de Análise Estatística para microcomputadores (ZONTA; MACHADO, 1986).

\section{Resultados e Discussão}

Para primeira contagem de germinação, teste de germinação e índice de velocidade de germinação (IVG) não ocorreu diferença em sementes normais (Tabela 1) em relação aos diferentes tamanhos (peneira $6,5 \mathrm{~mm} \mathrm{e}$ $5,75 \mathrm{~mm}$ ). As sementes esverdeadas maiores (peneira $6,5 \mathrm{~mm}$ ) têm maior percentual de primeira contagem de germinação, germinação total e IVG que as sementes esverdeadas menores (peneira $5,75 \mathrm{~mm}$ ), indicando que o tamanho da semente (maior massa) tem influencia positivamente no processo de germinação das sementes, em decorrência do maior vigor.

As sementes normais apresentaram maior primeira contagem de germinação, germinação total e índice de velocidade de germinação em relação às sementes esverdeadas nos diferentes tipos de peneira. As sementes esverdeadas apresentam uma germinação menor que $80 \%$ fator descarta a possibilidade de comercialização das mesmas; resultados semelhantes encontrados por Zorato et al. (2007). Pádua et al. (2007) e Rangel et al. (2011) verificaram que os acréscimos dos percentuais de sementes verdes provocam redução acentuada da germinação.

Tabela 1. Desdobramento da análise de variância para a primeira contagem de germinação, germinação e índice de velocidade de germinação de sementes de soja em função do tamanho e do esverdeamento das sementes. UEMS, Cassilândia/MS, 2014.

\begin{tabular}{|c|c|c|}
\hline \multirow{2}{*}{ Tipo de sementes } & \multicolumn{2}{|c|}{ Tamanho das sementes } \\
\hline & Peneira $6,5 \mathrm{~mm}$ & Peneira $5,75 \mathrm{~mm}$ \\
\hline & \multicolumn{2}{|c|}{$1^{\circ}$ contagem germinação $(\%)$} \\
\hline Normais & ${ }^{\mathrm{M}} 80 \mathrm{aA}$ & $85 \mathrm{aA}$ \\
\hline Esverdeadas & $48 \mathrm{bA}$ & $27 \mathrm{bB}$ \\
\hline DMS & \multicolumn{2}{|c|}{6,00} \\
\hline C.V.(\%) & \multicolumn{2}{|c|}{7,75} \\
\hline & \multicolumn{2}{|c|}{ Teste de germinação (\%) } \\
\hline Normais & $89 \mathrm{aA}$ & $89 \mathrm{aA}$ \\
\hline Esverdeadas & $54 \mathrm{bA}$ & $30 \mathrm{bB}$ \\
\hline DMS & \multicolumn{2}{|c|}{6,00} \\
\hline C.V.(\%) & \multicolumn{2}{|c|}{7,60} \\
\hline
\end{tabular}

Índice de velocidade de germinação (IVG)

\begin{tabular}{ccc} 
Normais & $8,69 \mathrm{aA}$ & $8,75 \mathrm{aA}$ \\
Esverdeadas & $5,21 \mathrm{bA}$ & $2,91 \mathrm{bB}$ \\
\hline \multicolumn{1}{c|}{ DMS } & & 0,85 \\
\hline \multicolumn{1}{c|}{ C.V.(\%) } & 8,69
\end{tabular}

${ }^{\mathrm{M}}$ Médias seguidas de letras diferentes maiúsculas nas linhas e minúsculas nas colunas, diferem estatisticamente entre si pelo teste $\mathrm{F}$ a $5 \%$ de probabilidade. 
As condições edafoclimáticas durante o período de desenvolvimento das plantas a campo, especialmente durante o estádio de maturação, pode causar a formação de sementes esverdeadas as quais têm influência direta no potencial fisiológico das sementes. Desta forma, a maturação forçada das sementes provenientes de distúrbios fisiológicos nas plantas pode causar características indesejáveis do ponto de vista do seu potencial germinativo.

A quantidade de exsudatos liberados no teste de condutividade elétrica (Tabela 2) para as sementes normais e esverdeadas apresentaram diferença em função do tamanho da semente, onde a peneira $5,75 \mathrm{~mm}$ liberou mais exsudatos (maior condutividade elétrica), decorrente do menor vigor das sementes, visto que a massa das sementes tem influência direta no vigor das sementes. Em relação aos tipos de sementes nas diferentes peneiras utilizadas, se verifica que as sementes normais apresentaram menor condutividade elétrica em relação as esverdeadas, comprovando menor potencial fisiológico das sementes esverdeadas, resultados semelhantes encontrados por Zorato et al. (2007).

O teste de condutividade elétrica avalia a quantidade de exsudatos presente na solução de embebição das sementes, assim quanto maior a quantidade, maior o valor da condutividade. Sementes esverdeadas que foram produzidas em condições de maturação inadequadas provavelmente propiciarão sementes de menor vigor ou maior condutividade elétrica (sistema de membranas com maior desorganização e com mais danos). Semente com maior vigor (maior tamanho) tem maior capacidade de reorganização e reparação dos danos nas membranas durante a reidratação das sementes; consequentemente apresentará menor leitura de condutividade elétrica.

Para o teste de emergência de plântulas e índice de velocidade de emergência de plântulas em areia (Tabela 2) a porcentagem e velocidade de plântulas emergidas não foram influenciadas em relação ao tamanho de peneira para sementes normais. Para as sementes esverdeadas, o maior tamanho (peneira $6,5 \mathrm{~mm}$ ) possibilitou a maior porcentagem e velocidade de emergência quando comparado as sementes de menor tamanho (peneira $5,75 \mathrm{~mm}$ ). Estes resultados corroboram com os resultados encontrados no teste de germinação, os quais confirmam maior vigor em sementes maiores. Quanto ao tipo da semente, no tamanho menor das sementes (peneira 5,75) $\mathrm{mm}$ se verificou maior emergência de plântulas e IVE em sementes normais, não ocorrendo o mesmo as de 6,5 $\mathrm{mm}$, que não apresentaram influência do tipo de sementes. Zorato, et al. (2007) verificaram baixo potencial de emergência em sementes esverdeadas.

Tabela 2. Desdobramento da análise de variância referente a condutividade elétrica, emergência de plântulas e índice de velocidade de emergência de plântulas de soja função do tamanho e esverdeamento das sementes. UEMS Cassilândia (MS), 2014.

\begin{tabular}{|c|c|c|c|}
\hline & \multirow{2}{*}{ Tipo de sementes } & \multicolumn{2}{|c|}{ Tamanho das sementes } \\
\hline & & Peneira $6,5 \mathrm{~mm}$ & Peneira $5,75 \mathrm{~mm}$ \\
\hline & & \multicolumn{2}{|c|}{ Condutividade elétrica $\left(\mu \mathrm{S} \mathrm{cm}^{-1} \mathrm{~g}^{-1}\right)$} \\
\hline Normais & & ${ }^{\mathrm{M}} 110,1 \mathrm{bB}$ & $142,9 \mathrm{bA}$ \\
\hline Esverdeadas & & $193,7 \mathrm{aB}$ & $264,4 \mathrm{aA}$ \\
\hline & DMS & \multicolumn{2}{|c|}{17,91} \\
\hline & C.V.(\%) & \multicolumn{2}{|c|}{6,54} \\
\hline & & \multicolumn{2}{|c|}{ Emergência de plântulas (\%) } \\
\hline Normais & & $54 \mathrm{aA}$ & $69 \mathrm{aA}$ \\
\hline Esverdeadas & & $41 \mathrm{aA}$ & $15 \mathrm{bB}$ \\
\hline & DMS & \multicolumn{2}{|c|}{16,00} \\
\hline & C.V.(\%) & \multicolumn{2}{|c|}{18,66} \\
\hline & & \multicolumn{2}{|c|}{ Índice de velocidade de emergência (IVE) } \\
\hline Normais & & $5,05 \mathrm{aA}$ & $6,49 \mathrm{aA}$ \\
\hline Esverdeadas & & $3,99 \mathrm{aA}$ & $1,68 \mathrm{bB}$ \\
\hline & DMS & \multicolumn{2}{|c|}{1,97} \\
\hline 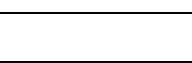 & C.V.(\%) & \multicolumn{2}{|c|}{29,87} \\
\hline
\end{tabular}

${ }^{\mathrm{M}}$ Médias seguidas de letras diferentes maiúsculas nas linhas e minúsculas nas colunas, diferem estatisticamente entre si pelo teste $\mathrm{F}$ a $5 \%$ de probabilidade. 
Pelo teste de emergência de plântulas foi evidenciado que as sementes apresentavam baixo vigor, independentemente do tratamento a que foi submetida. Pádua et al. (2010) verificaram que as sementes normais classificadas em diferentes tamanhos apresentam diferenças em qualidade fisiológica, onde sementes maiores apresentam maiores porcentagens de germinação e de vigor. Todavia, Piccinin et al. (2012) verificam que as sementes de soja normais classificadas nas peneiras $5,5 \mathrm{~mm}$ e $6,5 \mathrm{~mm}$ apresentam similaridade no potencial fisiológico das sementes, resultados semelhantes encontrados no presente estudo.

As sementes normais apresentam maior qualidade fisiológica do que as esverdeadas, pois o esverdeamento das sementes implicou em menor percentual e velocidade de germinação; características que podem inviabilizar a sua comercialização. O tamanho das sementes esverdeadas (tipo de peneira) influenciou seu potencial fisiológico, em que sementes com maior massa apresentaram maior germinação e vigor. De acordo com França-Neto et al (2012) ficou evidente que a ocorrência do esverdeamento da semente de soja prejudica a sua qualidade fisiológica.

\section{Conclusões}

Sementes de soja esverdeadas apresentam menor potencial fisiológico.

O maior tamanho da semente esverdeada melhora sua qualidade fisiológica.

\section{Referências Bibliográficas}

ÁVILA, W.; PERIN, A.; GUARESCHI, R. F.; GAZOLLA, P. R. Influência do tamanho da semente na produtividade de variedades de soja. Agrarian, Dourados-MS, v.1, n.2, p.8389, 2008.

BRASIL. MINISTÉRIO DA AGRICULTURA, PECUÁRIA E ABASTECIMENTO. Regras para análise de sementes. Ministério da Agricultura, Pecuária e Abastecimento. Secretaria de Defesa Agropecuária. Brasília-DF: Mapa/ACS, 2009. 395p.

FRANÇA-NETO, J. B.; PADUA, G. P.; COSTA, O.; BRUMATTI, P. S. R.; KRZYZANOWISK, F. C.; COSTA, N. P.; HENNING, A. A.; SANCHES, D. P. Sementes esverdeadas e sua qualidade fisiológica. Londrina-PR: Embrapa Soja, 2005. 8p. (Circular Técnica, 38).
FRANÇA-NETO, J. B.; PADUA, G. P.; KRZYZANOWSKI, F. C.; CARVALHO, M. L. M.; HENNING, A. A.; LORINI, I.; Semente esverdeada de soja: causas e efeitos sobre o desempenho fisiológico - série sementes. Londrina-PR: Embrapa soja, 2012. 16p. (Circular Técnica, 91).

MAGUIRE, J. D. Speed of germination aid in selection and evaluation for seedling and vigour. Crop Science, Madison, v.2, n.2, p.176-177, 1962.

PÁDUA, G. P.; FRANÇA-NETO, J. B.; CARVALHO, M. L. M.; COSTA, O.; KRZYZANOWSKI, F. C.; COSTA, N. P. Tolerance level of Green in soybean seed lots after storage. Revista Brasileira de Sementes, Londrina-PR, v. 29, n. 3, p. 128-138, 2007.

PÁDUA, G. P.; ZITO, R. K.; ARANTES, N. E.; FRANÇANETO, J. B.; Influência do tamanho da semente na qualidade fisiológica e na produtividade da cultura da soja. Revista Brasileira de sementes, Londrina-PR, v. 32 , n. 3, p. $9-16$, 2010.

PICCININ, G. G.; DAN, L. G. M.; RICCI, T. T.; BRACCINI, A. L.; BARBOSA, M. C.; MOREANO, T. B.; HORVATHY NETO, A.; BAZO, G. L. Relação entre o tamanho e a qualidade fisiológica e sanitária de sementes de soja. Revista Agrarian, Dourados-MS, v. 5, n. 15, p. 20-28, 2012.

RANGEL, M. A. S.; MINUZZI, A.; PÍEREZAN, L.; TEODÓSIO, T. K. C.; ONO, F. B.; CARDOSO, P. C.; Presença e qualidade de sementes esverdeadas de soja na região sul do Estado de Mato Grosso do Sul. Acta Scientiarum Agronomy, Maringá-PR, v. 33, n. 1, p. 127-132, 2011.

VIERA, R.D.; KRYZANOWSKI, F.C. Teste de condutividade elétrica. In: KRYZANOWSKI, F.C.; VIEIRA, R.D.; FRANÇA NETO, J.B. (Ed.). Vigor de sementes: conceitos e testes. Londrina-PR: ABRATES, 1999. p.4-1.

ZONTA, E.P.; MACHADO, A.A. Sistema de Análise Estatística para microcomputadores - SANEST. Pelotas: UFPel, Instituto de Física e Matemática, 1986. 150p.

ZORATO, M. F.; PESKE, S. T.; TAKEDA, C.; FRANÇANETO, J. B. Presença de sementes esverdeadas de soja e seus efeitos sobre seu potencial fisiológico. Revista Brasileira de Sementes, Pelotas-PR, v. 29, n. 1, p. 11-19, 2007. 